\title{
Jean-Christian Pleau, Bernanos: la part obscure
}

\section{Emanuele Kanceff}

\section{Q OpenEdition}

\section{Journals}

\section{Edizione digitale}

URL: https://journals.openedition.org/studifrancesi/41118

DOI: 10.4000/studifrancesi.41118

ISSN: 2421-5856

\section{Editore}

Rosenberg \& Sellier

\section{Edizione cartacea}

Data di pubblicazione: 1 juillet 2004

Paginazione: 219

ISSN: 0039-2944

\section{Notizia bibliografica digitale}

Emanuele Kanceff, «Jean-Christian Pleau, Bernanos: la part obscure», Studi Francesi [Online], 142 (XLVIII | I) | 2004, online dal 30 novembre 2015, consultato il 09 septembre 2021. URL: http:// journals.openedition.org/studifrancesi/41118; DOI: https://doi.org/10.4000/studifrancesi.41118

\section{Questo documento è stato generato automaticamente il 9 septembre 2021.}

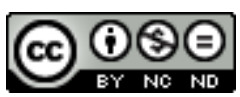

Studi Francesi è distribuita con Licenza Creative Commons Attribuzione - Non commerciale - Non opere derivate 4.0 Internazionale. 


\title{
Jean-Christian Pleau, Bernanos: la part obscure
}

\author{
Emanuele Kanceff
}

\section{NOTIZIA}

JEAN-CHRISTIAN PLEAU, Bernanos: la part obscure, New York, Peter Lang, 1998, pp. 134

(«Currents in Comparative Romance Languages and Literatures», 56).

1 L'autore parte dalla constatazione che la critica recente non dedica una sufficiente attenzione all'opera di Bernanos. Romanziere cattolico, egli potrebbe sembrare uno scrittore a tesi, e ciò ridurrebbe di molto il reale interesse della sua scrittura. Questo studio, che segue una tesi di dottorato sostenuta alla Yale University, si propone di interrogare la «parte oscura» dell'opera del grande romanziere, ovvero quanto si sottrae alle riduzioni ideologiche e ne forma la grandezza: «Le temps paraît donc venu de reprendre les romans de Bernanos, de les interroger autrement que pour y retrouver la confirmation d'un dogme donné d'avance, et extérieur au texte». Il cammino di riflessione dell'autore passa dai rapporti fra sogno e realtà alla divisione verbale, dall'analisi delle anime oscure a quella dell'engagement, alla sparizione del senso (Monsieur Ouine), per concludersi sulle prospettive che ci permettono, oggi, di leggere questa opera romanzesca dall'eterna fortuna. Non resta che sperare che le previsioni di Jean-Christian Pleau possano trovar conferma nei fatti. 